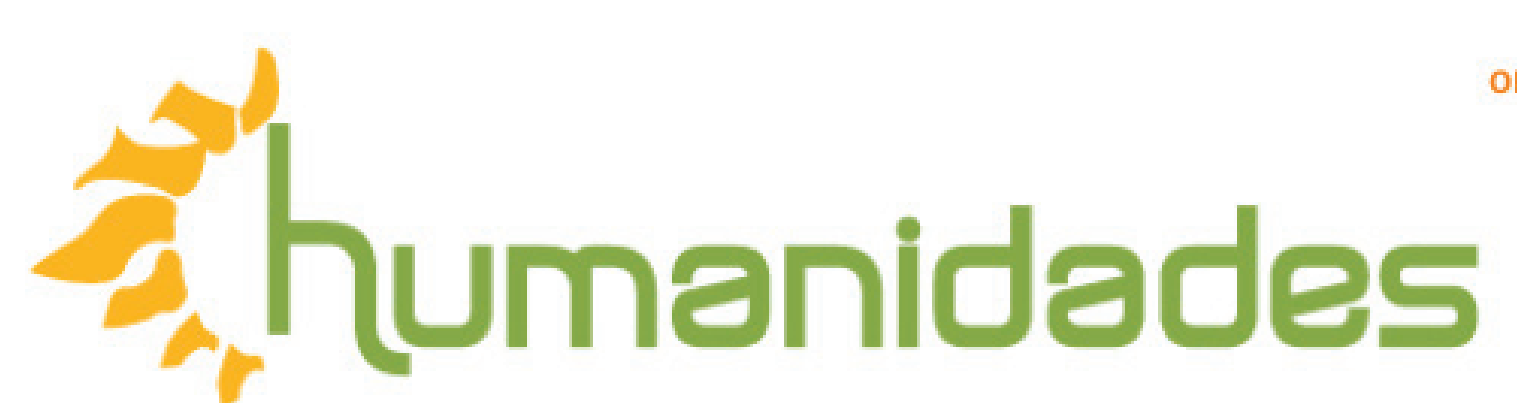

Revista de la Escuela de Estudios Generales, Universidad de Costa Rica

Julio-diciembre, 2018 •Volumen 8, número 2 • EISSN 2215-3934•pp. 1 - 34

Recibido: 01-Diciembre-2017 Aceptado: 18-Enero-2018

\title{
La Pornografía en la obra de Andrea Dworkin: mujer y desconexión moral
}

DOI: https://doi.org/10.15517/h.v8i2.33674

\section{Manuel José Rengifo Streeter}

Magíster en Filosofía Aplicada y Magíster en Psicología. Profesor de la Escuela de Psicología, Universidad de los Andes, Chile.

Correo electrónico: mjrengifo@uandes.cl

Todos los derechos reservados. Universidad de Costa Rica. Esta revista se encuentra licenciada con Creative Commons. Reconocimiento-NoComercial-SinObraDerivada 3.0 Costa Rica. Correo electrónico: humanidades@ucr.ac.cr/ Sitio web: http: //revistas.ucr.ac.cr/index.php/ humanidades 


\title{
La Pornografía en la obra de Andrea Dworkin: mujer y desconexión moral
}

\section{Resumen}

Pocas activistas feministas llegaron tan lejos como Andrea Dworkin (19462005) en la lucha por la censura de la pornografía. En el presente artículo se aborda la denuncia de la autora sobre la deshumanización de la mujer en la pornografía como producto del poder del hombre dentro de la cultura patriarcal occidental. Paralelamente, se ofrece un correlato de la propuesta de Dworkin con los mecanismos psicológicos de desconexión moral propuestos por Albert Bandura. Finalmente, y como producto de la metodología descrita, se discute la obra de Dworkin, su análisis de la hostilidad hacia la mujer, los eventuales mecanismos psicológicos subyacentes a la producción y consumo de pornografía, y el rol de cierto tipo de cultura que perpetuaría estas dinámicas.

\section{Pornography in the Works of Andrea Dworkin: women and moral disengagement}

\begin{abstract}
Few feminist activists went as far as Andrea Dworkin did (1946-2005) in the struggle for censorship of pornography. This article addresses the author 's claim about the dehumanization of women in pornography as a product of man' s power within the Western patriarchal culture. At the same time, in the current paper Dworkin's proposal will be linked with the psychological mechanisms of moral disengagement proposed by Albert Bandura. Finally, as a product of the methodology described, the work of Dworkin is discussed, as well as her analysis of hostility towards women, the possible psychological mechanisms underlying the production and consumption of pornography, and the potential role of a certain type of culture in perpetuating those dynamics.
\end{abstract}

Palabras claves:

Dworkin, feminismo, pornografía, deshumanización, moral.
Keywords:

Dworkin, feminism, pornography, dehumanization, moral. 


\section{Introducción al movimiento anti-pornografía de Andrea Dworkin}

Andrea Dworkin (nacida en Candem, Nueva Jersey, escritora y activista feminista radical, 1946- 2005) puede ser considerada como una de las personas más influyentes en la batalla contra la violencia de género hacia la mujer. El feminismo radical, del cual Dworkin es una de sus principales exponentes, propone una absoluta rebelión a la violencia del hombre sobre la mujer representada en el rol de sumisión que la mujer ocupa en la cultura patriarcal. Esta posición social sería patente en el lugar secundario de la mujer en el campo laboral, económico, político, legal, y cultural. El feminismo radical acusa la violencia del hombre hacia la mujer como el único vehículo para continuar su supremacía. Por lo tanto, para el feminismo radical no será posible una nueva - y justa - realidad hasta que exista un reordenamiento de la sociedad en donde esta dialéctica desaparezca y el patriarcado sea definitivamente abolido.

En consecuencia, la obra literaria y social de Dworkin aborda el amplio espectro de la figura femenina como objeto de la dominación masculina, sobre todo en la cultura patriarcal occidental. En esta empresa, Dworkin destaca (junto con Catherine MacKinnon, abogada y también feminista) respecto de otras activistas por su tenaz batalla en contra de la producción de pornografía como fuente de violencia en contra de las mujeres. Concretamente, Dworkin y MacKinnon fueron las impulsoras del Movimiento Anti-Pornografía que buscó erradicar la pornografía en los Estados Unidos por la vía legal invocando la violación de los derechos civiles. Esta iniciativa la llevó a ser duramente criticada tanto por sectores políticos como por otras falanges del mismo movimiento feminista, quienes le reprocharon promover la censura. Sin embargo, la iniciativa legal tuvo éxito en el Estado de Indianápolis el año 1983, siendo aprobada. No obstante, poco más tarde, la presión de la industria pornográfica hizo que el Tribunal Supremo de los Estados Unidos fallara en contra de la ley y la declarara nula. 
No es solo fue su férreo activismo en contra de la violencia hacia la mujer, que la pornografía promovería, lo que merece ser destacado en Dworkin. En un nivel conceptual más profundo, esta autora pudo exponer con un modo directo, crudo y a veces hasta melodramático, las inclinaciones sexuales agresivas que serían las bases de la imposición de un poder, percibido como innato en lo masculino, que justificaría y exigiría el dominio por parte del hombre, y la consiguiente sumisión de la mujer a él. En este sentido, Dworkin va más allá de la mera defensa del liberalismo por cualquier manifestación de la sexualidad humana dentro de los límites de la libertad entendida como posibilidad electiva. La autora entiende que en la pornografía se representa un contenido a nivel simbólico que perpetúa y valida la deshumanización de la figura femenina. En Pornography: Men Possesing Women (1981), obra representante de su ideología por antonomasia, Dworkin expone con genialidad y acrimonia única los principios de poder adjudicados al género masculino (tanto por el hombre, la mujer y, en general, la cultura) que perpetuarían las dinámicas sexuales-eróticas en nuestros días y que violarían crónicamente la dignidad de la mujer, deshumanizándola.

Como fue mencionado anteriormente, la obra de esta autora no fue solo desacreditada por algunos segmentos políticos y religiosos, críticas esperables cabe señalar, sino que también por segmentos feministas liberales (Parent, 1990). Desde ese flanco, las activistas reprocharon la concepción de Dworkin acerca de la pornografía tildándola de conservadora, represora de la sexualidad femenina, esencialista, entre otros calificativos (Benn, 1993; Mui, 1980; Vadas, 1987). Para dichas feministas, la autora da una mirada sesgadamente represiva de la sexualidad, reduciéndola casi en su totalidad a una conducta de mera dominación e incluso violación heterosexual.

En la narrativa de Dworkin, están presentes incluso críticas extremas a ciertas figuras e instituciones cívicas básicas de la cultura, las cuales según esta autora están desvirtuadas por ser un engendro de la misma cultura patriarcal a la cual ataca sin cesar. Por ejemplo, el matrimonio sería una institución que se desarrolla o concreta por la práctica de la violación (Dworkin, 1987). Este tipo de afirmación podría sugerir que la autora busca deliberadamente un estilo narrativo directo y confrontacional que genera impacto aún a riesgo de perder precisión. 


\section{Objetivos y metodología}

El objetivo y alcance teórico de la presente investigación es, primero, describir el pensamiento de la autora en relación con la pornografía, sus alcances culturales y su impacto en la potencial violación de los derechos de la mujer. En segundo lugar, se ofrece de modo complementario información recogida de la investigación científica sobre el eventual impacto psicológico de la pornografía en las personas. Finalmente, se muestra la relación de ciertos aspectos de su obra con unos procesos cognitivos definidos por la psicología social, específicamente en los procesos de desconexión moral descritos por Albert Bandura dentro de su Teoría Socio Cognitiva. De esa forma, se intentará mostrar cómo la evidencia disponible y estos procesos psicológicos permiten respaldar la tesis de la autora, reflejándola en un encuadre social contemporáneo occidental.

\section{La pornografía como discurso de odio hacia la mujer}

Como explica Dworkin, la palabra "pornografía” proviene de las palabras griegas porné y graphos, las cuales significan "escritura (o cualquier representación gráfica) sobre prostitutas" (Dworkin, 1981: 199). Si bien es cierto la autora deja el término expresado en sentido amplio en toda su obra, para efectos de un adecuado abordaje es útil citar la definición de un tipo de pornografía que ofrece Brison: “... Discurso de odio violento, degradante y misógino (en el cual la palabra "discurso" incluye palabras, imágenes, películas, etc.)" (citado en Coleman \& Held, 2014: 89- 103).

De esta definición, es fundamental recoger la idea que la inicia: "discurso de odio" (a la mujer). Sin embargo, por décadas el énfasis del desencuentro entre activistas anti-pornografía y anti-censura giraba en torno al eventual menoscabo moral o degradación de aquellos agentes involucrados en la pornografía. Cabría preguntarse entonces, ¿se degrada a la "mujer" ?, o ¿aquellos que la representan en la pornografía son los que estarían siendo degradados? 
En términos del calificativo "degradante", algunos sectores feministas señalan que la degradación es sufrida por quienes producen el material pornográfico. Por otra parte, también hay autores anti-pornografía que señalan que sería el consumidor de pornografía quien se degradaría (Scruton, 1986: 27). En la obra de Dworkin esta disyuntiva no está desarrollada posiblemente porque la autora daría por descontado que la fabricación y consumo de pornografía son productos de agentes que ya estarían degradados por el solo hecho de ser representantes y defensores de una cultura desviada. De todos modos, sean ambas o una de estas alternativas, es relevante considerar lo propuesto por Benn en su trabajo "Pornography: Degradation and Rhetoric" (1993) por presentar una línea argumentativa que parece ser similar al mensaje de Dworkin al distinguir el análisis retórico de uno meramente concreto.

Lo que se degrada no sería la "mujer" en cuanto persona, sino que lo que se degradaría sería el concepto de lo "femenino". Efectivamente, también Mui (1980: 126) señala esta misma idea recalcando que en la pornografía la mujer "es la antítesis del sujeto libre que existe mediante la trascendencia a su cuerpo por medio de sus propias posibilidades. Precisamente porque la mujer nunca es un sujeto en particular [en el material pornográfico], la pornografía no cosificaría a la mujer, sino que a la idea de mujer".

Años después, en la década de los setenta, la discusión sobre la pornografía comenzó a girar ya no tanto sobre el efecto potencialmente degradante en sus productores, protagonistas o en sus consumidores. La disputa se centró en la esfera de los derechos, entre quienes abogaban por una irrestricta libertad de expresión y quienes manifestaban fervientemente que la pornografía representaba un discurso de odio, homologable, por ejemplo, al discurso de odio racista. Consecuentemente a esta última posición, el material pornográfico se diferenciaría de otro tipo de material gráfico en que éste tendría como ethos la reproducción de contenido sexual explícito y, complementariamente, quien usa pornografía la consumiría con fines eróticos y consciente de los objetivos de sus productores (Benn, 1993). Susan Brownmiller, periodista y feminista estadounidense, expresó que "la pornografía es la esencia sin diluir de la propaganda contra las mujeres" (1976:394). 
Complementariamente, para poder establecer el rango del concepto "pornografía" al que la obra de Dworkin se aboca, bien vale utilizar la delimitación que la misma autora junto con MacKinnon presentaron en la tramitación legal de la Ordenanza de Derechos Civiles contra la Pornografía (Dworkin \& MacKinnon, 1988). Ambas autoras pusieron especial énfasis en la definición legal de pornografía en la confección de esta ordenanza. Cabe señalar que esta delimitación perseguía fines legales y que, por lo mismo, carece de cierta rigurosidad analítica (Vadas, 1987). Considerando lo anterior, en este proyecto legal se caracteriza la pornografía como una forma de "discriminación sexual" y en virtud de ello define lo siguiente:

“1. Por "pornografía” se entiende la subordinación gráfica sexualmente explícita de las mujeres a través de imágenes y/o palabras que también incluye uno o más de los siguientes:

a. Mujeres que son presentadas deshumanizadas como objetos, cosas o mercancías sexuales; o

b. Mujeres que son presentan como objetos sexuales que disfrutan de la humillación o el dolor; o

c. Mujeres que son presentadas como objetos sexuales que experimentan placer sexual en la violación, incesto u otra agresión sexual; o

d. Mujeres que son presentadas como objetos sexuales atados o cortados, mutilados, magullados o dañados físicamente; o

e. Mujeres que se presentan en posturas o posiciones de sumisión sexual, servilismo o exhibición; o

f. Partes del cuerpo de las mujeres -que incluyen, pero no se limitan, a vaginas, senos o nalgas- que se exhiben de modo que las mujeres son reducidas a esas partes; o

g. Mujeres que son presentadas siendo penetradas por objetos o animales; o h. Mujeres que son presentadas en escenarios de degradación, humillación, lesión, tortura, mostradas como sucias o inferiores, sangrantes, magulladas o heridas en un contexto que hace que estas condiciones sean sexuales.

2. El uso de hombres, niños o transexuales en lugar de las mujeres en (a) (h) dentro de esta definición, es también pornografía para los propósitos de la ley. 3. El concepto "Persona” incluirá además a los niños y a los transexuales". (Dworkin \& MacKinnon, 1988:101). 
Finalmente, desde la fallida iniciativa legal de la dupla Dworkin-MacKinnon hasta la fecha, la producción de material pornográfico no solo ha aumentado, sino que se ha constituido en una industria de miles de millones de dólares en ganancias anuales. Hoy esta industria se ha beneficiado de múltiples agentes para su masificación: regulaciones legales (o falta de), adopción cultural de la pornografía como bien de consumo, avances tecnológicos contemporáneos que han ampliado enormemente las posibilidades de producción, y canales de distribución instantáneos de todo tipo de material audio/visual con acceso anónimo e instantáneo (Paasonen, 2014).

Existiría hasta hoy, en definitiva, una cultura que ha ido adoptando a la pornografía a través del tiempo. Es en gran medida a esta cultura a quien Dworkin ataca por haber permitido y fomentado la deshumanización de la mujer a través de múltiples vías, siendo la pornografía uno de sus estandartes.

\subsection{Cultura patriarcal y dominio sobre la mujer}

La mujer no nace; se hace. En la fabricación, su humanidad es destruida. Ella se convierte en símbolo de esto y de aquello: madre de la tierra, puta del universo; pero nunca se convierte en "ella", porque le está prohibido hacerlo. Ningún acto suyo puede alterar el modo en que se la percibe constantemente: como una especie de cosa (Dworkin, 1981: 128).

Estas palabras de Dworkin reflejan su lectura acerca de la manera en que la cultura patriarcal ha construido, y al mismo tiempo negado, el concepto de mujer. Aún más, en la pornografía la mujer se actualizaría en virtud de dicha construcción social. En ese marco, el simbolismo mismo de su "naturaleza", definida desde los principios con los que el hombre ha cimentado esta cultura, cumpliría con su meta en un sinfín de posibilidades que solo tendría límite en la creatividad del consumidor (Dworkin, 1981).

La cultura patriarcal se afirmaría en unas bases que declaran la supremacía del hombre. Dworkin (1981) nombra y describe siete principios básicos mediante los cuales es posible comprender la ideología machista. Primero, la necesidad expansionista del hombre. Él se siente con el derecho a poseer, a ampliarse. 
Lo cree propio y natural. Por extensión, la mujer no posee este principio y se "ofrece" a ser poseída por el hombre. Segundo, el hombre es físicamente más fuerte que la mujer. Por lo tanto, él tiene dominio efectivo sobre ella y la toma, por la fuerza. Tercero, el hombre es biológicamente agresivo, inherentemente combativo, genéticamente cruel y hostil. Cuarto, el hombre en su posición de poder domina el lenguaje. Así, tiene la posibilidad de modelar su realidad, de nombrar las cosas y fenómenos del mundo. Quinto, el hombre asume que tiene por derecho el dominio de la mujer, desde siempre y para siempre. Sexto, el dinero expresa masculinidad. El dinero simboliza el derecho natural del hombre a poseer, adquirir. Séptimo, el hombre tiene el poder sobre el sexo. Sin embargo, ellos expresan lo contrario: dicho poder reside en la mujer, por lo que la ven como un sinónimo de sexo.

En la cultura patriarcal el hombre tendría por naturaleza un rol de poder y dominio sobre la creación. En vías de lograr efectivamente esa posición, Dworkin expone que desde niño el hombre aprende a deshumanizar y cosificar a la mujer por medio de la violencia. Esta sería la manifestación natural del poder masculino. Es solo mediante ese aprendizaje que tanto el hombre como la mujer se actualizarían dentro de esta cultura. Si bien es cierto que la autora a través de su obra se refiere al hombre perteneciente a la cultura patriarcal/machista, no queda claro si, implícitamente, está caracterizando a todos los hombres ya que, según ella, el peso de esta cultura está presente desde los albores de la humanidad. En este sentido Dworkin, en el fondo, incluye a todos los hombres sin hacerlo explícitamente. Tampoco queda claro según sus escritos si en algún sitio, al menos en occidente, existe otro tipo de cultura que no sea patriarcal. Además, y como hemos expresado antes, la autora extrema sus argumentos para crear impacto. De esa manera, cae en un sesgo de atribución disposicional respecto a la naturaleza del hombre (en cuanto sujeto masculino) al reducirlo como sujeto que solo tiene posibilidades de expresarse desde y por medio de la agresividad.

En adición, la cultura patriarcal favorecería el fenómeno por excelencia que le demostraría al hombre su posición de dominio natural. En la palabra de Dworkin (1987: 203-204): el "coito". El coito sería una forma de posesión en la cual el hombre habita o más bien "conquista" el cuerpo de la mujer a través de la penetración. 
Así, él la hace "suya" y ella, por extensión, se "rinde" o entrega a él; de esta forma el dominio elemental del hombre sobre la mujer queda sellado. En dicha conquista, la mujer "valoraría" el poder y la fuerza masculina de manera a veces pasiva o a veces activa. Ella rendiría homenaje al poder al no oponer resistencia o bien en su resistencia activa. Estaría solicitando que el hombre hiciera explícito su poder para, de la misma forma, rendir admiración al despliegue de tal “don”. En esta fórmula, la cultura patriarcal sellaría la condena metafísica del destino de toda mujer, el ser vista como la responsable de la violencia recibida. ¿Por qué recibe tal violencia? "Porque le gusta, a todas les gusta" (Dworkin, 1981: 148). Además, la pornografía solo sería la manifestación simbólica de una realidad evidente por sí misma. Según Dworkin, sería exactamente de esa manera. En la pornografía se representaría precisamente eso: un simbolismo propio de la cultura que la alberga. La autora hace hincapié en el término "simbolismo" y en su diferencia con la mera "fantasía" cuando describe la pornografía. Esta diferencia es crucial en su obra, por cuanto por "simbolismo" Dworkin se refiere a un contenido que se representa como símil de la realidad, que tiene raíces directas en ella y que genera efectos.

Por el contrario, la "fantasía" escapa a la realidad, se desvanece una vez terminado su relato o presentación (Dworkin, 1981: 29, 200-201). Esta diferencia es fundamental cuando la autora rebate el argumento acerca de la pornografía creada para ser consumida por las mujeres. Este argumento se basa en remarcar que también hay producción de pornografía orientada al público femenino y que, por ende, sería erróneo decir que la pornografía per se representa siempre la sumisión de la mujer. A esto, Dworkin responde que ese tipo de pornografía se basa solo en "fantasías" que presentan a la mujer en una posición de poder en donde sus deseos eróticos serían satisfechos. Así, este tipo de material no tendría un valor simbólico $\mathrm{y}$, por lo mismo, tampoco impacto en la realidad.

Según Dworkin, lo simbólico representaría tanto el poder, la agresividad del hombre como el deseo masoquista de la mujer de ser conquistada. El masoquismo es intrínsecamente provocación y sumisión. La ideología patriarcal justificaría entonces la violencia en contra de la mujer y, al mismo tiempo la haría invisible. A la falta de evidencia sobre la sumisión voluntaria y silenciosa de la mujer por la violenta conquista del hombre, 
lacultura machista respondería precisamente con su reverso: el silencioy lo oculto son partesfundamentalesdelmasoquismofemenino. Nohaydañoniviolación, pueselacto se consuma o realiza en el uso "natural" de ambas partes: conquistador y conquistada.

\subsection{Movimiento liberal feminista: anti-pornografía, anti-censura y pornografía feminista}

Como fue enunciado al principio, una de las batallas más feroces que enfrentó Dworkin no fue necesariamente con los sectores conservadores, quienes criticaban su obra casi en su totalidad, sino que con agrupaciones de ideología liberal. Concretamente, con las feministas radicales anti- censura. Éstas critican las propuestas de Dworkin por considerarlas censuradoras y regresivas. Estaría, en última medida, abogando por la misma censura hacia la pornografía que los sectores conservadores ligados a la derecha y a la Iglesia Católica.

Asimismo, en su obra se encuentran fragmentos específicamente presentados como contra argumentación a la posición liberal. Según la autora, la ideología liberal de izquierdas afirma que "la libertad sexual está en el uso irrestricto de las mujeres, el uso de las mujeres como un recurso natural colectivo, no privatizado, no propiedad de un solo hombre, sino que utilizado por muchos" (Dworkin, 1981). Como contra parte, las agrupaciones feministas anti-censura defienden la pornografía no tanto como "pornografía en sí", sino que como manifestación válida de la libre expresión. Sorprendentemente, muchas feministas anti-censura reconocen que la pornografía está en gran medida inspirada bajo la ideología de la cultura patriarcal, pero sin embargo no adhieren al discurso "moralizante" de Dworkin y compañía (Mui, 1980). Estas feministas anti-censura critican la posición de los movimientos anti-pornografía ya que estarían delimitando la sexualidad a un concepto de "normalidad" que pondría en la otra vereda a la pornografía como una manifestación "pervertida".

Actualmente, esta polémica se encuentra lejos de estar prescrita. Incluso, autoras como Gayle Rubin o Camille Paglia reclaman por un rescate de la sexualidad libre como elemento fundamental de nuestra sociedad. Por ejemplo, Rubin critica la politización 
politización del sexo como instrumento de poder y control por parte de la sociedad occidental. Según esta autora, la cultura patriarcal ha endosado injustamente al sexo características negativas e incluso peligrosas. Sería esta construcción la que ha degradado a la sexualidad y a sus manifestaciones, entre ellas la pornografía (Rubin, 1984). En esta misma línea, la producción y consumo de pornografía feminista ha experimentado un auge en los últimos años. Annie Sprinkle, actriz pornográfica y defensora del feminismo pro-pornografía, declara que el sexo y sus manifestaciones no solo deben ser estudiados, sino acogidos por la sociedad como expresiones humanas naturales. La pornografía feminista debería ser acogida como vehículo en la exploración de una gratificación sexual natural e igualitaria (más sobre Annie Sprinkle en Williams, 1993) De hecho, según la directora de pornografía feminista Tristán Taormino, "la pornografía feminista responde a la imagen de la dominancia de dos maneras: creando imágenes alternativas y desarrollando una nueva iconografía de la sexualidad" (Taormino, 2013).

Aun reconociendo el carácter patriarcal del material pornográfico, los movimientos anti-censura estarían por inclinarse, en última medida, por defender un bien superior: la expresión de la diversidad sexual. En ese sentido, conceden un valor potencial a la plataforma pornográfica como una base que entregaría la posibilidad de expresar esta diversidad. Sin embargo, no queda claro cómo la pornografía podría dar cabida a esa manifestación manteniendo su ethos, o sea, sin reducir o deshumanizar a quienes fueran sus protagonistas, productores o consumidores. En la misma línea de Dworkin, muchas feministas consideran que el tipo de material sexual explícito en pornografía degrada y cosifica a la mujer (i.e. a la idea de mujer) teniendo como efecto la posible generación de actitudes favorables a la coerción y explotación sexual (Brownmiller, 1975; Morgan, 1980). Esta posición expone una preocupación por la potencial extensión de los efectos del consumo privado a la esfera pública.

Estas agrupaciones a la cuales Dworkin combate, verían la pornografía como un género en evolución que tendría la posibilidad de introducir una perspectiva alternativa para las mujeres y las minorías sexuales. Pero ¿qué pasa cuando la libertad de expresión se manifiesta como vehículo de un discurso que daña a terceros? Dworkin recoge esta problemática para graficar cómo, por ejemplo, su iniciativa legal fue truncada y desechada legalmente por, supuestamente, atentar contra el derecho de libre expresión. 
Según la autora, ese sería un ejemplo de que la defensa de dicho derecho termina por ser la defensa tuerta de un formalismo (Dworkin, 1987: 73; 1989: 211). Sería más relevante, expone la autora, preservar y cuidar dicha libertad que atender a su contenido y al daño a la dignidad de otros que éste pudiera causar. Este argumento se apoyaría, además, en la imposibilidad práctica de catalogar y establecer qué material pornográfico específico constituiría una transgresión a la dignidad de las personas y cuál no. Según las mencionadas agrupaciones anti-censura, ese ejercicio de categorización caería en lo meramente subjetivo y por ende no clasificable. ¿Cómo “estandarizar" los contenidos sin caer en un complejo puritanismo ético? Ante esto, Dworkin alega que la defensa de la forma siempre resultará más sencilla, pero por lo mismo también estará vacía de realidad. Según ella "no hay nada tan peligroso como un principio incorpóreo: no importa qué sangre fluya, el principio viene primero" (Dworkin, 1989: 212).

Por otra parte, ciertas agrupaciones liberales han defendido la voluntariedad de los actos representados en la pornografía, así como el consentimiento de los consumidores al elegir ese tipo de material. Además, defienden la imposibilidad de establecer una norma ética transversal a todo material pornográfico ya que sería imposible determinar, en cada caso, si la "actriz" (o alguien más) estaría sufriendo o siendo dañada. Por su parte, Dworkin cree que esa posición se basa en una falacia. Según la autora, esos argumentos esconden un relativismo en donde lo fundamental sería, en última medida, la actitud que la mujer "escogería" durante el acto y su eventual experiencia placentera o desagradable a posteriori: si ella sufre, sería una víctima, pero si ella se entrega y participa del goce, entonces es libre (Dworkin, 1981).

Ante este tipo de argumentación liberal cabe hacerse al menos una evidente pregunta: lo que separa, en este caso, lo bueno de lo malo ¿es la aceptación del rol sexual, o la experiencia que se tiene y sus consecuencias? Acá no hay, al parecer, noción de bien o dignidad, sino solo delgados matices totalmente específicos a la situación y que se interpretan bajo la ilusión de una voluntad que, puesta en acto, solo puede ser leída como la manifestación de la libertad individual. Pero ¿cómo puede ser la libertad dependiente solo de los resultados o consecuencias de la acción? 
La libertad es anterior a la conducta; es más: la impulsaría para ganar más libertad (Millán-Puelles, 1995). Sería una contradicción que dependa del producto. Sería una libertad encadenada y azarosa.

Otra línea argumental defendida por agrupaciones anti-censura que Dworkin intenta desarticular, es el eventual carácter "lúdico" de la pornografía. A este supuesto valor, esta autora responde que efectivamente puede llegar a ser divertido para sus productores, protagonistas y, ciertamente para sus consumidores, pero no así para las mujeres que nada tienen que ver con la pornografía y que, a raíz de las consecuencias de estaa, podrían verse afectadas por la potencial cosificación o deshumanización que de ella se desprende (Dworkin, 1989: 278). Paralelamente, se le ha criticado también no considerar que en la pornografía a veces se presenta a la mujer en una posición dominante, o incluso sádica. Dicho argumento sería una prueba que desmitificaría la supuesta tiranía del hombre sobre la mujer y por consiguiente la omnipotencia de la cultura patriarcal dibujada por esta autora.

A este argumento, Dworkin responde que la mujer en posición sádica representaría, en el fondo, el rol de castigadora del hombre por su incapacidad de desempeñar su rol masculino: ser agresor. En este sentido, la mujer debe representar una inversión de los papeles para llevar a cabo dos roles paralelos: primero, castigar al hombre por el incumplimiento de su rol agresor/masculino (y el consiguiente castigo por no tratar a la mujer como "debe" ser tratada) y, en segundo lugar, servir de modelo para representar las conductas y actitudes masculinas/dominantes que su pareja debiera asumir. Es casi una manifestación "ética": prescribe y proscribe roles y conductas sociales, propias de un paradigma cultural (Dworkin, 1989: 240)

Después de lo expuesto en estas líneas cabría aun preguntarse por qué la pornografía sería distinta a otras manifestaciones "artísticas" en cuanto a la cosificación o deshumanización de la mujer. Mui (1980) ofrece una reflexión esclarecedora a esta pregunta. Según esta autora, a diferencia de las películas o del contenido ofrecido en televisión que eventualmente podrían también presentar a la mujer como un objeto, la pornografía posicionaría a la mujer deliberadamente fuera del sujeto, sin posibilidades ni intenciones de representarla como tal. En la pornografía, la mujer no representaría un personaje construido con las características que podríamos asociar a un sujeto. 
Lo presentado en este tipo de material no concede al personaje de elementos básicos como rasgos psicológicos, personalidad, historia, relaciones interpersonales dentro de un contexto social, entre otros. El personaje ofrecido en la pornografía no hace eco de una persona (ni intenta hacerlo), sino que es un cuerpo y existe solo como tal. Dworkin agregaría a este argumento un matiz no menos relevante. Esa manera de representar a la mujer simbolizaría una construcción de un fenómeno que sí es real: la mujer a los ojos de la cultura patriarcal.

\subsection{Impacto por la exposición repetida a material pornográfico: datos aportados por la investigación}

Según el reporte sobre sexualización de la mujer publicado por la APA el año 2007 (Task Force on the Sexualization of Girls, 2007), la sexualización de la mujer en la cultura ha tenido diversos efectos negativos. Si bien es cierto se consigna que los efectos a largo plazo o sus posibles alcances aún no han podido ser proyectados de forma definitiva, algunos de sus consecuencias son patentes. Dentro de estos efectos producidos por la sexualización que cosifica a la mujer podemos destacar secuelas desadaptativas en las mujeres jóvenes. Entre éstas podemos observar que, considerándose a ellas mismas como objetos eróticos, fragmentan su autoconcepto, disminuyen su autoestima, tiene un mayor riesgo de abandonar sus proyectos académicos, y muestran bajos niveles de tolerancia a la frustración.

El excesivo foco en la imagen corporal y en las expectativas impuestas (propias y externas) a dicha imagen que muchas veces son inalcanzables y derechamente poco saludables, puede provocar sentimientos de vergüenza, ansiedad, y asco hacia el propio cuerpo. Estos síntomas estarían a la base de ciertos cuadros especialmente prevalentes en mujeres jóvenes. Entre estos cuadros podemos encontrar los trastornos de la conducta alimentaria, baja autoestima y cuadros depresivos, entre otros.

Es relevante señalar que la metodología de este reporte se focaliza en población estadounidense. Sin embargo, se considera relevante para el análisis por la enorme influencia que la cultura de dicho país aún tiene sobre la mayoría de las sociedades occidentales. 
Otros estudios han agregado valiosa evidencia que apoyaría la preocupación por los efectos negativos de la pornografía expresados por Dworkin. Por ejemplo, diversos estudios realizados previo a la masificación de internet han señalado que la exposición al tratamiento mediático de la agresión sexual estaría vinculada a la aceptación de los mitos de la violación (Linz \& Malamuth, 1993; Malamuth \& Check, 1985) y a menos compasión por la víctima (Ramirez, Bryant, \& Zillmann, 1982). En esa misma línea, la exposición prolongada a material pornográfico estaría asociado a una mayor aceptación de la violencia contra las mujeres (Berkowitz, Burkhart, \& Bourg, 1994; Donnerstein, 1980; Malamuth \& Check, 1985). A su vez, la exposición a material sexual explícito se relacionaría con la percepción de que la pareja resulte menos atractiva sexualmente (Weaver, Masland, \& Zillmann, 1984) y, a la vez, se reportaría menos satisfacción en términos de su apariencia física y desempeño sexual (Zillmann \& Bryant, 1988).

Complementariamente, la evidencia no solo se ha circunscrito a estudios específicos, sino que también sería concordante con diferentes meta-análisis que abarcan amplios datos y variadas investigaciones en la era digital. Wright, Tokunaga y Kraus (2016) estudiaron 22 estudios correspondientes a datos obtenidos de investigaciones en siete países (EE.UU., Italia, Taiwán, Brasil, Noruega, Suecia y Canadá), entre los años 1993 a 2014. Las muestras estudiadas correspondieron a un total de 20.820 personas, incluyendo tanto hombres como mujeres, adolescentes y adultos. El objetivo de este meta-análisis fue observar la potencial relación entre consumo de pornografía y agresión sexual.

Los resultados de este meta-análisis indican que "existen pocas dudas de que, en promedio, los individuos que consumen pornografía tienen más probabilidades (y frecuencia) de tener actitudes conducentes a agresiones sexuales y más probabilidades de involucrarse en actos sexualmente agresivos en comparación con personas que no consumen pornografía o que la consumen con menor frecuencia". (Wright et al, 2016: 201)

Los resultados obtenidos por Wright et al, son concordantes con otros estudios y metaanálisis. De hecho, Smith et al (2016), realizaron un meta-análisis que incluyó 14 estudios correspondientes a un total de 20.781 personas, hombres y mujeres entre los 10 y 24 años, de 5 países (EE.UU., Taiwán, Holanda, Nigeria y Suiza), entre los años 2005 a 2014 
Los estudios transversales analizados por Wright et al mostraron una fuerte asociación entre la exposición a contenidos sexuales en los medios y las conductas sexuales de los jóvenes, tales como relaciones sexuales sin protección, consumo de alcohol y drogas, y el involucramiento con múltiples parejas sexuales. Estos estudios sugieren, entre otras cosas, que los jóvenes serían una cohorte especialmente sensible a la exposición de este tipo de material ya que correrían el riesgo de desarrollar creencias y valores sexuales poco realistas (Owens, Behun, Manning, \& Reid, 2012).

En definitiva, la evidencia da luz sobre un efecto dañino expansivo, temor que también está presente en la obra de Dworkin en la figura de la estigmatización: "Estar marcado por la sexualidad significa que la experiencia tiene efectos" (Dworkin, 1987). En este sentido, la sexualidad como experiencia y como acto configuraría el sí mismo, al igual que las otras experiencias y conductas del ser humano. Así, la marca de una sexualidad experimentada (en mayor o menor medida) en la pornografía, afectaría el sí mismo. Sería ingenuo pensar que esa experiencia solo se desenvuelve en la esfera de lo lúdico, o que es exclusivo del ámbito exploratorio, del reino de las fantasías eróticas y que nada tienen que ver con otros ámbitos privados o públicos. El establecimiento de este tipo de estigma podría marcar a fuego la experiencia vital y pondría en riesgo el desarrollo personal a la posibilidad de caminos más integradores y maduros, dirigiéndolo a rutas escindidas y desligadas de un proyecto vital unificado.

\section{Violencia de género y desconexión moral}

Dworkin ha remarcado que la posición de poder del hombre se cimienta progresiva y constantemente en su entorno vía aprendizaje social. Es así como la autora critica la eventual incongruencia de sus detractores liberales. Por un lado, este grupo habría siempre defendido el valor de la educación, pero, de manera increíble, negaría el efecto de la pornografía como elemento potencial de aprendizaje de conductas sexuales, “... se nos pide que creamos que nada pornográfico, ya sea escrito o visual, tiene un efecto educativo en una persona" (Dworkin, 1989: 208). 
Desde la perspectiva de la Teoría Socio Cognitiva (Bandura, 1986) se entiende esencial la interrelación de las conductas y del ambiente en el aprendizaje social. En este caso, el consumo de pornografía es reforzado por un ambiente que circunscribiría la pornografía como libre expresión de la sexualidad, y su consumo como la adscripción libre y voluntaria a un producto que solo representaría fantasías que tienen como utilidad la exploración sexual. Pero, como hemos expuesto hasta ahora, la evidencia nos muestra que lo que estaría siendo aprendido e internalizado en el consumo de pornografía serían actitudes que están lejos de la mera recreación. La misma cultura patriarcal nutriría el círculo vicioso del hombre como perpetuador de un dominio agresivo sobre la mujer.

\subsection{Desconexión moral}

La investigación en psicología social ha descrito diferentes factores que ayudan a explicar cómo las personas podemos mantener una sensación de bienestar psicológico incluso después de haber transgredido alguna norma moral. Algunos de estos factores son la desconexión moral (Bandura, 2002; Bandura, Barbaranelli, Caprara, \& Pastorelli, 1996), el autocontrol (Mead, Baumeister, Gino, Schweitzer, \& Ariely, 2009), los factores del ambiente (Gino, Ayal, \& Ariely, 2009), los factores cognitivos (Pizarro \& Bloom, 2003), y la falta de consciencia (Batson, Thompson, Seuferling, Whitney, \& Strongman, 1999), entre otros. Entre los mencionados arriba, quizás uno de los procesos más estudiados en el comportamiento poco ético ha sido la desconexión moral.

La desconexión moral se ha definido como el proceso cognitivo por el cual una persona puede comportarse de una manera que no refleja sus propios estándares morales internos, sin sentirse estresado al respecto (Bandura et al., 1996). Por ejemplo, en términos de autoestima, el comportamiento deshonesto podría ser una amenaza para el Yo, porque socavaría la propia auto- imagen moral de la persona. Así, con el fin de proteger al Yo, esa persona intentaría racionalizar o replantear ese comportamiento a través de la desconexión moral (Bandura, 2002).

Este proceso de desvinculación moral opera a través de diferentes mecanismos que prácticamente "desconectan" los estándares morales de una persona de la posible interpretación ética de la conducta. 
Complementariamente, Bandura describe este proceso como inserto en una interacción triádica de elementos que impactan en la auto-regulación de la conducta moral, entre otros posibles comportamientos sociales. A saber: los determinantes del ambiente/contexto social, los determinantes de la persona, y los determinantes de las conductas y el aprendizaje. La interacción de estos tres factores es denominada por este autor como el "sistema de causación recíproco" (Bandura, 2016). Así, podemos advertir que el comportamiento moral no solo responde a factores internos (conscientes o inconscientes) de la persona, sino que es además influido por elementos de su entorno, ya sean personas, condiciones físicas del ambiente, o estímulos de diferentes fuentes emisoras, por nombrar algunos.

Al mismo tiempo, las conductas y el aprendizaje que la persona desarrolla son también producto de las mencionadas interacciones y su propia configuración. Finalmente, cada persona también impacta y altera a su entorno reconfigurándolo y reconfigurándose. En ese sentido, y conectando con nuestro tema de interés particular que es la pornografía en la obra de Dworkin, podemos advertir una problemática actual que podría leerse desde lo postulado por Bandura: hoy, legal y socialmente, la pornografía estaría implícitamente aceptada como un material válido y disponible para quien quiera consumirlo privadamente.

Es necesario recalcar que los procesos de desconexión moral no tienen como función alterar los estándares morales, sino que más bien proporcionar los medios a aquellas personas que se desconectan moralmente, permitiéndoles despojarse de la moralidad de sus comportamientos dañinos y de su responsabilidad por ellos. Sin desmedro de lo anterior, y en concordancia con la Teoría Socio Cognitiva, debemos precisar que la habituación de ciertas conductas puede llevar a un cambio progresivo en los principios que la norman. Específicamente, la desconexión moral es un proceso cognitivo que, al igual que otros procesos cognitivos, puede influir en las bases del aprendizaje, pues impacta en el desenvolvimiento de las conductas. En consecuencia, a mayor nivel y cantidad en el uso de este proceso, mayores posibilidades de involucramiento en conductas antisociales (Bandura et al., 1996). 


\subsection{Mecanismos de desconexión moral}

Los mecanismos de desconexión moral descritos por Bandura son divididos en virtud de diferentes focos de la acción. En lo que sigue, se presentarán la totalidad de los mecanismos descritos por Bandura y una breve descripción de los mismos. Más delante, nos enfocaremos sobre todo en los mecanismos de deshumanización y de culpar de la víctima, ya que son aquellos que estarían más representados en la obra de Dworkin.

\subsubsection{Foco en la conducta}

Justificación moral, social o económica de la conducta: Mediante este mecanismo, la conducta inhumana se transformaría en personal y socialmente aceptable al ser interpretada en el marco de un propósito socialmente digno o de una jerarquía moral superior (Bandura, 2002). Podemos ver cómo mecanismos de este tipo son descritos en la obra de Dworkin, por ejemplo, en su análisis de la obra del Marqués de Sade. Para el Marqués, el abuso queda justificado ya que salvaguarda un "bien" superior: la liberación sexual.

Uso de eufemismos: El lenguaje eufemístico proporciona un dispositivo conveniente para enmascarar actividades reprochables o incluso para darles un carácter respetable (Bandura, 1991). Así mismo, Lutz (1987) propone que las "maquinaciones" eufemísticas se usan ampliamente para separar y despersonalizar al agente de las actividades dañinas a las cuales se refiere. De la misma forma, los defensores de la pornografía la nombran usando eufemismos tales como "liberación de la sexualidad femenina", "libre expresión de las fantasías eróticas", entre otras. Este uso de eufemismos esconde un simbolismo que reflejaría un paradigma basado en el ya mencionado poder del hombre sobre el lenguaje, uno de los principios que destaca Dworkin sobre la cultura patriarcal.

Comparación ventajosa: Este mecanismo consiste en la contraposición de conducta dañinas con otras más perniciosas aún. De esa forma, el comportamiento puede asumir una calidad diferente dependiendo de con qué se contrasta; incluso podrían aparecer como justos y apropiados (Bandura, 2016). 
Un ejemplo de este mecanismo sería la comparación que podría hacer un hombre adulto que fuerza a su pareja a tener relaciones sexuales, con las violaciones de los pedófilos. En este caso, la agresión en contra de la voluntad de su pareja se enmarcaría en lo esperable dentro de una relación amorosa y sería un hecho menor en comparación con otras agresiones sexuales tales como las violaciones pedófilas. De esa manera, el hombre contrasta su propia conducta con otra de mayor gravedad, normalizando así su comportamiento.

\subsubsection{Foco en el agente}

Desplazamiento de la responsabilidad: Cuando las personas operan bajo este mecanismo, consideran que sus acciones proceden de los dictados de las autoridades y, por lo mismo, no se consideran personalmente responsables de ellas (Bandura, 2002).Como ejemplo de este mecanismo, tenemos las justificaciones de Sade, descritas en la obra de Dworkin, hacia su compulsiva conducta de abusos sexuales y a la demanda que en su contra interpusieron los familiares de una joven por rapto y violación: "la dueña [procuradora] que me proporcionó a la muchacha, y que es perfectamente consciente de que está expresamente prohibido hacerlo, es la culpable. Esta acusación contra mí en Lyon de secuestro y violación fue totalmente ilegal" (Crosland, 1963, citado en Dworkin, 1981: 91). Aquí vemos como Sade desplaza la culpa en quien le proporcionó a la joven.

Difusión de la responsabilidad: El control moral se debilita cuando la agencia personal se oscurece por la difusión de la propia responsabilidad en conductas perjudiciales en un marco más amplio donde generalmente participan más personas (Bandura et al., 1996). Por ejemplo, en la toma de decisiones grupales que dañan dolosamente a terceros es una práctica relativamente común. Ello permitiría que los miembros de ese grupo puedan desprenderse de la completa responsabilidad por una conducta que es producto de varios agentes. El hecho que la pornografía haya existido por muchas décadas y que además haya sido masivamente consumida, entrega bases fértiles para este tipo de desconexión moral (Bandura, 2016). 


\subsubsection{Foco en los efectos}

Distorsión de las consecuencias: Este mecanismo consiste en minimizar o evitar hacerse cargo del daño que una persona ha generado a otra u otras. De esta forma evitan su responsabilidad (Bandura, 2002). Este tipo de mecanismo está representado en los debates de Dworkin en su crítica a sus contendoras feministas anti-censura. La autora les critica que buscar ocultar o minimizar los efectos perniciosos de la pornografía al tratarla como un "mal menor" en comparación con la defensa de la diversidad sexual y su libre expresión (Dworkin, 1989: 202).

\subsubsection{Foco en la víctima}

Deshumanización: Este concepto puede entenderse luego de definir ciertas características de lo que se entiende como propiamente "humano". Una propuesta interesante es la de Bastian y Haslam (2011). Según estos autores la "humanidad" se caracterizaría por ciertos factores esenciales presentes en mayor o en menor medida en todas las personas. Estas características incluyen la apertura a la experiencia, la emotividad, la calidez, y la vitalidad. Complementariamente, también se describen una serie de características que denotan la "singularidad humana", cualidades que distinguirían a los humanos de otros animales. Estas son el refinamiento, la civilidad, la capacidad cognitiva superior, y otras habilidades sociales aprendidas (Bastian \& Haslam, 2011; Haslam \& Stratemeyer, 2016).

Despojando las cualidades humanas a una persona o a un cierto grupo de personas, el agente agresor las percibe como seres infrahumanos, sin emociones o solo con las propias del salvajismo, sin habilidades intelectuales suficientes, sin proyectos vitales relevantes, entre otras cosas. Son vistas como grupos primitivos, degenerados, "cosas" animadas, en definitiva, subhumanos (Bandura, 2016: 84-89). De hecho, existe evidencia que refleja que las personas que ven a las mujeres como objetos, probablemente se excusen de su abuso emocional, violencia física e incluso violación, a través de este mecanismo de desconexión moral (Ohbuchi, Ikeda, \& Takeuchi, 1994). 
Complementariamente, existe evidencia del impacto de la cosificación de la mujer hacia la aceptación y hasta aprendizaje de ciertas actitudes deshumanizantes. Así, la exposición a medios de comunicación que repetidamente presentan a la mujer como un objeto, se relacionaría con la normalización del uso de la violencia hacia ella (Lee, Hust, Zhang, \& Zhang, 2010). Como complemento, la Teoría Socio Cognitiva de Bandura (Bandura, 2001) postula que las personas pueden aprender valores vicariamente a través de, por ejemplo, los medios de comunicación (Weaver, 1981). Por lo tanto, si la cosificación de la mujer se presenta de manera repetida como algo común podríamos esperar un aumento en la percepción de que la violencia sexual sería justificable (Berkowitz, Burkhart, \& Bourg, 1994). Es más, hay evidencia disponible que muestra de qué manera las imágenes sexualizadas de las mujeres activarían ciertas regiones del cerebro responsables del uso de objetos (Cikara, Eberhardt, \& Fiske, 2011).

La descripción de este mecanismo de desconexión moral es equivalente a lo que Dworkin caracteriza como la "cosificación de la mujer". La autora describe en sus escritos cómo la pornografía deshumaniza a la mujer. Más bien, cómo la cultura patriarcal representa en la pornografía una realidad de facto de la vida cotidiana. “La subordinación es cosificación”, enfatiza Dworkin (1981: 113). La sumisión discriminatoria de la mujer en la sociedad dominada por el hombre la despoja de poder disponer libremente de sí misma. La mujer queda entonces reducida a un objeto que puede ser reclamado y usado por la sociedad para los fines que estime conveniente, que no son otros que los fines que la cultura patriarcal tiene definidos para ella.

La pornografía producto de la cultura machista violenta a la mujer en sus términos, no agrede su libertad ya que ella no es libre. Los objetos no gozan de libertad (Dworkin, 1981; 1987: 177-178; 2000). En la realidad del hombre, dice la autora, la mujer no podría acceder a la consciencia masculina sin violarla. En ese caso, el hombre sería contaminado y alterado con cada contacto de una mujer que no se ajustase a su esquema masculino de mujer-cosa; no tendría patrones de conducta para esa situación. Sería inconcebible para el hombre considerar a la mujer como una igual con acceso al mundo de sus ideas. 
Consecuentemente se relaciona con ella en lo sexual a partir de la fijación en sus partes o de la fijación en su cuerpo-como-objeto. Cualquier clave que le permita al hombre configurar el contexto del encuentro sexual para cosificar a su pareja, y adicionalmente para evitar la vergüenza e incomodidad de la exposición propia del contacto íntimo, será bienvenida. Dworkin lo refleja en la siguiente escena: "la oscuridad lo conforta [al hombre] porque oscurece la personalidad; tiene relaciones sexuales en la oscuridad para convencerse de que todas las mujeres son iguales, sin sustancia ni importancia individual, a la Casanova" (Dworkin, 1981: 64). La mujer, entonces, se convierte en un fetiche sexual en cuanto ha sido parcializada y despojada de su humanidad. Ya no es solo un objeto, sino que además está cargada de un significado simbólico.

Finalmente, la respuesta automática o voluntaria del hombre a una o más partes específicas del cuerpo femenino y su fijación en ellas es vista por la ideología liberal solo como una manifestación válida de su individualidad, de sus preferencias sexuales. Dworkin critica que una mera preferencia sexual parcializada (en forma de fetiche, de encuentros sexuales fugaces, o de material sexual explícito) sea una manifestación válida y libre de la individualidad humana. Por el contrario, la describe como una parcialización de la individualidad.

La fijación en partes o fragmentos de una persona sería defendida por sus contendores como una manifestación subjetivamente válida cuando existe "acuerdo consciente" entre las partes. Pero al hacerlo, ¿no se niega, al menos psicológicamente, la individualidad integral de esa otra persona? y ¿cómo no pensar que las construcciones subjetivas no se plasman o manifiestan en lo social? Parecería ingenuo pensar que el mero consentimiento voluntario cubre y protege una experiencia de consecuencias no deseadas y que, además, la realidad subjetiva pueda ser totalmente escindida de la vida pública/social.

Atribución de la culpa: Este mecanismo descrito por Bandura se observa cuando el agente de un acto dañino culpa a la víctima por su propio comportamiento. No solo implica desplazar la responsabilidad, sino que, más específicamente, ese desplazamiento caería en quien ha sufrido la conducta agresiva o transgresora. De esa forma, el agresor puede no solo culpar a los terceros afectados, sino que además no sentir remordimientos al respecto (Bandura, 2002). 
Incluso este autor expone como la auto-exoneración también se logra cuando el autor acusa que su conducta ha sido forzada por condiciones inescapables. Esta atribución de la culpa a la víctima permite, de hecho, una inversión de los roles, convirtiendo al perpetrador en víctima (Bandura, 2016). Este fenómeno está desarrollado ampliamente en el trabajo de Dworkin cuando describe la adjudicación de la culpa por la violencia sexual del hombre a la mujer. Sería ella quien tendría el dominio sobre lo sensual. Desde ahí, la mujer incitaría al hombre a querer dar satisfacción a sus impulsos.

Ella es la provocadora por antonomasia, dueña de la llave que permite al hombre expresar su poder en el campo sexual de manera violenta ya que, según la cultura patriarcal, no habría otra manera. La mujer lo sabe, le gusta y lo pide (Dworkin, 1981: 179). Ella representa la figura castradora, dueña de tal poder sexual que no dudará en usarlo para intentar controlar al sexualmente desvalido y expuesto hombre. Pero ¡ay de ella si no controla su poder! La frustración del impulso sexual atrapado sin vías de satisfacción puede hacer que el hombre ejecute un castigo justo a tal provocación. Esto concuerda con los mitos de violación a los que nos referiremos a continuación, en donde se desplaza la responsabilidad de la violación a la mujer por ser dueña y controladora de este "poder" erotizante (Dworkin, 1981: 17-18).

Los mitos de violación son creencias erróneas, estereotipadas y prejuiciadas sobre las razones y dinámicas de las agresiones sexuales, los violadores y las víctimas de violación. Estos mitos se originarían a partir de diversos estereotipos culturales, tales como los roles tradicionales de género, la aceptación de la violencia interpersonal, y el malentendido sobre la naturaleza de la agresión sexual. Por ejemplo, dentro de los mitos que justifican la agresión sexual más comunes podemos encontrar frases como "ella se lo buscó", "si sales con esa ropa no alegues después", "ella estaba borracha", "todos sabemos que cuando una mujer dice «no», lo que realmente quiere decir es «sí»", entre otras. Consecuentemente, los mitos de violación son una de las principales fuentes de la adjudicación de responsabilidad a la víctima, de la minimización de la violación, y de la estigmatización de la femineidad. 
Las intervenciones educativas dirigidas a corregir las falsas creencias de los hombres sobre los mitos de violación podrían ayudar a romper la futura activación de mecanismos de desconexión moral como este (Vance, Sutter, Perrin, \& Heesacker, 2015).

\section{Una lucha sin fin}

¿Habrá alguien allí para implorar a la audiencia que la ayude a escapar de la ley de la pornografía - con o sin ley, con constitución o sin constitución?, ¿Comprenderá la audiencia que mientras la pornografía de ella exista, la mujer es cautiva de ella, fugitiva de ella? (Dworkin, 1997: 79)

En esta pregunta Andrea Dworkin advierte que esta es una pelea imperecedera, que seguirá presente quizás por décadas, incluso después de que ella misma muriera. Refleja en sus palabras una angustia casi claustrofóbica al advertir que la mujer se encuentra no solo en una cultura que quiere someterla, sino que dentro de una que ya la tiene apresada. Habría una realidad consumada, una en la que el hombre explota y la mujer es explotada. En este contexto, la mujer sufriría de una especie de Síndrome de Estocolmo del cual no ha podido salir, ni tampoco ha recibido ayuda para hacerlo.

Esta tarea no es fácil, Dworkin advierte que la metástasis de la cultura patriarcal avanza y que incluso ya habría extendido sus raíces a las mismas consciencias de las mujeres, quienes pasivamente e inconscientemente se han mimetizado con los símbolos construidos por esta sociedad. Es así, por ejemplo, como hoy se daría un hecho enigmático, una especie de fenómeno tácito en donde la posición del hombre se ratificaría en su dominio y poder: el hombre construye el mito que justifica su manera de crear símbolos, entre ellos, la sumisión absoluta de la mujer y su representación en la pornografía. En el otro lado de la moneda, la mujer no cree realmente que el hombre piense que ellas son, en el fondo, así. Esta negación por parte de la mujer es lo que perpetúa su condena. 
A este círculo vicioso Dworkin responde con furia y el gran grueso de su obra no va dirigida a acusar o increpar a los hombres, sino que está fundamentalmente dirigida a hacer un llamado de alerta, un despertar a las mujeres de esta falsa consciencia, de esta negación de una realidad que con su ingenuidad ayudarían a seguir construyendo.

Sin embargo, la cultura patriarcal no soltaría tan fácilmente su presa, a riesgo incluso de hacer gala de inconsistencias flagrantes en su argumentación sobre los derechos que la misma protege. Con el propósito de hacer patente tales contradicciones, Dworkin cita a Frederick Schauer, destacado profesor de Derecho, quien como testigo en la Audiencia de Pornografía y Derechos Civiles de 1992 expresó que "es una fuente constante de asombro que una sociedad que acepta tan fácil y correctamente la posibilidad de que un lindo dibujo de un camello pueda tener un efecto tal sobre el número de personas que fuman, tenga tanta dificultad para aceptar la proposición de que endosar imágenes de violación u otras formas de violencia sexual, pueda influir en el número de personas que cometa una violación" (Schauer, 1992, citado en MacKinnon y Dworkin, 1997: 396). Esta lógica (o falta de ella) se refleja incluso hoy cuando vemos una mayor rigurosidad en la presentación de ciertos productos potencialmente dañinos por su eventual efecto en el aprendizaje de malos hábitos en la población (e. g. alimentos altos en azúcar), que en el material erotizado y agresivo que a diario es posible encontrar en los medios, incluso en horario de protección a menores.

Específicamente, la masificación de internet - efecto potenciado por los dispositivos móviles - ha producido una explosión de la oferta pornográfica, y este medio ha pasado a ser el canal de elección por excelencia de material pornográfico en nuestros días, por encima de la producción gráfica en revistas. Si bien es cierto que internet ha incrementado la visibilidad y disponibilidad de pornografía a todo tipo de consumidores, el mayor consumidor continúa siendo, ampliamente, el segmento masculino heterosexual. La autora feminista Gail Dines ha puntualizado las repercusiones de este fenómeno en el desarrollo psicológico y social de los adolescentes tempranos. Dines ha destacado el potencial impacto negativo que tiene la pornografía como principal fuente de información sexual en la actualidad (2017). 
En relación con las consecuencias del uso de material sexual explícito, tanto el discurso de Dines como el de Andrea Dworkin, tienen asideros concretos apoyados por diferentes líneas de investigación actuales y que han sido resumidos en estas líneas. Adicionalmente, hemos podido ofrecer un modelo teórico que describe unos mecanismos cognitivos por los cuales una persona puede desconectarse de sus estándares morales luego de haber transgredido normas y dañado a terceros. Dichos mecanismos ayudan a describir fenómenos lúcidamente descritos por Dworkin a lo largo de toda su obra.

Específicamente, hemos podido analizar cómo la deshumanización/cosificación, sobre todo, en cuanto proceso cognitivo por el cual se le quita a una persona o grupo determinadas cualidades que la caracterizan como ser humano, estaría enraizada según la autora en la cultura patriarcal y sería la norma en la estereotipización de la mujer. Es más, según Dworkin no sería necesario la intención explícita del productor o consumidor de pornografía de causar un menoscabo a la mujer. Precisamente, la cultura machista ha validado una noción deshumanizada de la mujer que se ha internalizado en la sociedad. Además, mediante los procesos de desconexión moral que hemos descrito, el uso de la mujer en la pornografía ha sido sanitizado por medio de diferentes fórmulas, principalmente del discurso liberal anti-censura sobre la libertad de expresión sexual.

Cabe destacar, que los mecanismos de desconexión moral propuestos por Bandura no son excluyentes entre sí, pueden operar simultáneamente. De hecho, entre más procesos de este tipo se usen, más probabilidades habrá que la persona adopte conductas desviadas (Bandura, 1991). Adicionalmente, la ejecución repetida de los mecanismos de desconexión moral daría pie a una "pendiente resbaladiza" que podría desplazar a posiciones cada vez más permisivas los estándares morales antes más restrictivos. Por consiguiente, a mayor uso de los mecanismos, más débiles se harían las auto sanciones a través del tiempo.

Finalmente, leer y entender a Dworkin es una experiencia compleja desde un punto de vista analítico. Es difícil distinguir en ella su línea argumental de las características narrativas de su prosa. Dworkin repetidamente peca, quizás con la intención de resaltar un mensaje fuerte, casi a voz de grito, de lo que ella misma critica: el reduccionismo. 
En su dialéctica parece no haber lugar para los matices. Describe al hombre como opresor y le condena como reductor de la mujer a la categoría de objeto (por el poder que tiene en su posición jerárquica dentro de una cultura que él mismo ha construido y diseñado). Esta incongruencia argumental quizás fuera el precio que Dworkin aceptó pagar en pro de un objetivo mucho más estético y práctico que filosófico o argumental: poner los ojos del mundo en una realidad tan subterránea como dramática, la violencia sexual hacia la mujer; no solo aquella que se produce en los espacios públicos concretos, sino que también en los ámbitos privados e ideológicos de la sociedad occidental.

Aún en este ambiente de hostilidad, Dworkin ve una luz que habita en la mujer y que clama por un desenvolvimiento de la sexualidad en donde los amantes puedan encontrarse en todo su ser y no de forma parcializada. "La mujer aún desea una sensualidad más difusa, más tierna, que involucre a toda su corporalidad y a formas polimorfas de cariño" (Dworkin, 1987: 159). Así, reclama por la verdadera naturaleza, una en la que la mujer pueda experienciar su sexualidad integrada a los afectos.

\section{Referencias}

Allen, M., Emmers, T., Gebhardt, L., \& Giery, M. A. (1995). Exposure to pornog raphy and acceptance of rape myths. Journal of Communication, 45(1),

$5-26$.

Bandura, A. (1986). Social foundations of thought and action: a social cognitive theory. Englewood Cliffs, NJ: Prentice Hall.

Bandura, A. (1991). Social cognitive theory of moral thought and ation. Hand book of Moral Behavior and Development, 1, 1-46.

Bandura, A. (2001). Social Cognitive Theory of mass communication. Media Psychology, 3(3), 265-299. 
Bandura, A. (2002). Selective moral disengagement in the exercise of moral agency. Journal of Moral Education, 31(2), 101-119.

Bandura, A. (2016). Moral disengagement: how people do harm and live with themselves. Worth Publishers.

Bandura, A., Barbaranelli, C., Caprara, G. V., \& Pastorelli, C. (1996).

Mechanisms of moral disengagement in the exercise of moral agency. Journal of Personality and Social Psychology, 71(2), 364- 374.

Bastian, B., \& Haslam, N. (2011). Experiencing dehumanization: cognitive and emotional effects of everyday dehumanization. Basic and Applied Social Psychology, 33(4), 295-303.

Batson, C. D., Thompson, E. R., Seuferling, G., Whitney, H., \& Strongman, J. A. (1999). Moral hypocrisy: appearing moral to oneself without being so. Journal of Personality and Social Psychology, 77(3), 525-537.

Benn, P. (1993). Pornography, degradation and rhetoric. Cogito, 127-134.

Berkowitz, A. D., Burkhart, B. R., \& Bourg, S. E. (1994). Research on college men and rape. New Directions for Student Services, 1994(65), 3-19.

Brownmiller, S. (1976). Against our will: men, women, and rape. Bantam Books.

Cikara, M., Eberhardt, J., \& Fiske, S. (2011). From agents to objects: sexist attitudes and neural responses to sexualized targets. Journal of Cognitive Neuroscience, 23(3), 540-551.

Coleman, L., \& Held, J. M. (2014). The philosophy of pornography: contemporary perspectives. New York, United States: Rowman \& Littlefield.

Dines, G. (2017). Dignity: A Journal on Sexual Exploitation and Violence Growing Up with Porn: The Developmental and Societal Impact of Pornography on Children. Dignity: A Journal on Sexual Exploitation and Violence, 2(3). 
La Pornografía en la obra de Andrea Dworkin...

Donnerstein, E. (1980). Aggressive erotica and violence against women. Journal of Personality and Social Psychology, 39(2), 269-277.

Dworkin, A. (1981). Pornography: men possessing women. New York: Perigee Books.

Dworkin, A. (1987). Intercourse. Basic Books.

Dworkin, A. (1989). Letters from a war zone: writings, 1976-1989. E.P. Dutton.

Dworkin, A. (1997). Life and death. Free Press.

Dworkin, A. (2000). Scapegoat: the Jews, Israel, and women's liberation. Free Press.

Dworkin, A., \& MacKinnon, C. A. (1988). Pornography and civil rights: a new day for women's equality. Organizing Against Pornography.

Festinger, L. (1957). A theory of cognitive dissonance. Stanford University Press.

Gino, F., Ayal, S., \& Ariely, D. (2009). Contagion and differentiation in unethical behavior: The effect of one bad apple on the barrel. Psychological Science, 20(3), 393-398.

Haslam, N., \& Stratemeyer, M. (2016). Recent research on dehumanization. Current Opinion in Psychology, 11, 25-29.

Kelman, H. G. (1973). Violence without moral restraint: reflections on the dehumanization of victims and victimizers. Journal of Social Issues, 29(4), $25-61$.

Lee, M. J., Hust, S., Zhang, L., \& Zhang, Y. (2010). Effects of violence against women in popular crime dramas on viewers' attitudes related to sexual violence. Mass Communication and Society, 14(1), 25-44. 
Linz, D., \& Malamuth, N. (1993). Pornography. Communication Concepts.

Lutz, W. (1987). Language, appearance and reality: doublespeak in 1984. ETC: A Review of General Semantics, 44(4), 382-391.

MacKinnon, C., \& Dworkin, A. (1997). In harm's way. Massachusetts: Harvard University Press.

Malamuth, N. M., \& Check, J. V. P. (1985). The effects of aggressive pornography on beliefs in rape myths: individual differences. Journal of Research in Personality, 19(3), 299-320.

Mazar, N., \& Ariely, D. (2006). Dishonesty in everyday life and its policy implications. Journal of Public Policy \& Marketing, 25(1), 117-126.

Mead, N. L., Baumeister, R. F., Gino, F., Schweitzer, M. E., \& Ariely, D. (2009). Too tired to tell the truth: self-control resource depletion and dishonesty. Journal of Experimental Social Psychology, 45(3), 594-597.

Millán-Puelles, A. (1995). El valor de la libertad. Ediciones Rialp.

Mui, C. (1980). Rethinking the pornography debate: some ontological considerations. Bulletin de La Société Américaine de Philosophie de Langue Française, 10(2), 118-127.

Ohbuchi, K.-I., Ikeda, T., \& Takeuchi, G. (1994). Effects of violent pornography upon viewer's rape myth beliefs: A study of Japanese males. Psychology, Crime \& Law, 1(1), 71-81.

Owens, E. W., Behun, R. J., Manning, J. C., \& Reid, R. C. (2012). The impact of internet pornography on adolescents: a review of the research. Sexual Ad diction \& Compulsivity, 19(1-2), 99-122.

Paasonen, S. (2014). Diagnoses of transformation: "pornification," digital media, and the diversification of the pornographic. En L. Coleman, \& J. M. Held. (Ed.). The philosophy of pornography: contemporary perspectives (pp. 3-16). New York, United States: Rowman \& Littlefield. 
Parent, W. A. (1990). A second look at pornography and the subordination of women. The Journal of Philosophy, 9(September 1987), 205-211.

Pizarro, D. a, \& Bloom, P. (2003). The intelligence of the moral intuitions: comment on Haidt (2001). Psychological Review, 110(1), 193-196-198.

Ramirez, J., Bryant, J., \& Zillmann, D. (1982). Effects of erotica on retaliatory behavior as a function of level of prior provocation. Journal of Personali ty and Social Psychology, 43(5), 971-978.

Rubin, G. (1984). Thinking sex: Notes for a radical theory of the politics of sexuality. In Social Perspectives in Lesbian and Gay Studies: A Reader (Vol. 12, pp. 100-133).

Scruton, R. (1986). Sexual Desire: A Philosophical Investigation. Continuum.

Smith, L. W., Liu, B., Degenhardt, L., Richters, J., Patton, G., Wand, H., ... Guy, R. (2016). Is sexual content in new media linked to sexual risk behaviour in young people? A systematic review and meta-analysis. Sexual Health, 13(6), 501-515.

Task Force on the Sexualization of Girls, A. P. A. (2007). Report of the APA Task Force on the Sexualization of Girls APA Task Force on the Sexualization of Girls. American Psychological Association, 1-72.

Taormino, T. (2013). The feminist porn book: the politics of producing pleasure. Feminist Press at the City University of New York.

Vadas, M. (1987). A first look at the pornography/civil rights ordinance: could pornography be the subordination of women? The Journal of Philosophy, 84(9), 487-511.

Vance, K., Sutter, M., Perrin, P. B., \& Heesacker, M. (2015). The media's sexual objectification of women, rape myth acceptance, and interpersonal violence. Journal of Aggression, Maltreatment \& Trauma, 24(April), $569-587$. 
Weaver, D. H. (1981). Media agenda-setting in a Presidential election: issues, im ages, and interest. Praeger.

Weaver, J. B., Masland, J. L., \& Zillmann, D. (1984). Effect of erotica on young men's aesthetic perception of their female sexual partners. Perceptual and Motor Skills, 58(3), 929-930.

Williams, L. (1993). A Provoking Agent : The Pornography and Performance Art of Annie Sprinkle Author. Social Text, (37), 117-133.

Wright, P. J., Tokunaga, R. S., \& Kraus, A. (2016). A Meta-Analysis of

Pornography Consumption and Actual Acts of Sexual Aggression in General Population Studies. Journal of Communication, 66(1), 183-205.

Zillmann, D., \& Bryant, J. (1988). Pornography's impact on sexual satisfaction. Journal of Applied Social Psychology, 18(5), 438-453.

\section{¿Cómo citar este artículo?}

Rengifo Streeter, M.J. (Julio-diciembre, 2018). La Pornografía en la obra de Andrea Dworkin: mujer y desconexión moral. Revista humanidades, 8 (2), 1-34. 